\title{
Nanostructured TiC Layer is Highly Suitable Surface for Adhesion, Proliferation and Spreading of Cells
}

\author{
Mariangela Lopreiato ${ }^{1}\left(\mathbb{D}\right.$, Alessia Mariano ${ }^{1}$, Rossana Cocchiola ${ }^{1,+}{ }^{\oplus}$, Giovanni Longo ${ }^{2}{ }^{(0}$, \\ Pietro Dalla Vedova ${ }^{3}$, Roberto Scandurra ${ }^{1}$ and Anna Scotto d'Abusco ${ }^{1, *}$ (D) \\ 1 Department of Biochemical Sciences, Sapienza University of Roma, P.le Aldo Moro, 5, 00185 Roma, Italy; \\ mariangela.lopreiato@uniroma1.it (M.L.); alessia.mariano@uniroma1.it (A.M.); \\ rossana.cocchiola@gmail.com (R.C.); roberto.scandurra@fondazione.uniroma1.it (R.S.) \\ 2 Consiglio Nazionale delle Ricerche-Istituto di Struttura della Materia, Via del Fosso del Cavaliere, 100, \\ 00133 Rome, Italy; giovanni.longo@artov.ism.cnr.it \\ 3 UOC di Ortopedia e Traumatologia, Ospedale Santa Scolastica di Cassino, ASL di Frosinone, Via S. Pasquale, \\ 03043 Cassino, Italy; pietro.dallavedova@aslfrosinone.it \\ * Correspondence: anna.scottodabusco@uniroma1.it; Tel.: +39-06-4991-0947 \\ † Current affiliation: Clinical Trial Unit, Bambino Gesù Children's Hospital, IRCSS, P. Sant'Onofrio 4, \\ 00100 Roma, Italy.
}

Received: 17 March 2020; Accepted: 7 April 2020; Published: 10 April 2020

check for updates

\begin{abstract}
Cell culture is usually performed in 2D polymer surfaces; however, several studies are conducted with the aim to screen functional coating molecules to find substrates more suitable for cell adhesion and proliferation. The aim of this manuscript is to compare the cell adhesion and cytoskeleton organization of different cell types on different surfaces. Human primary fibroblasts, chondrocytes and osteoblasts isolated from patients undergoing surgery were seeded on polystyrene, poly-D-lysine-coated glass and titanium carbide slides and left to grow for several days. Then their cytoskeleton was analyzed, both by staining cells with phalloidin, which highlights actin fibers, and using Atomic Force Microscopy. We also monitored the production of Fibroblast Growth Factor-2, Bone Morphogenetic Protein-2 and Osteocalcin, using ELISA, and we highlighted production of Collagen type I in fibroblasts and osteoblasts and Collagen type II in chondrocytes by immunofluorescences. Fibroblasts, chondrocytes and osteoblasts showed both an improved proliferative activity and a good adhesion ability when cultured on titanium carbide slides, compared to polystyrene and poly-D-lysine-coated glass. In conclusion, we propose titanium carbide as a suitable surface to cultivate cells such as fibroblasts, chondrocytes and osteoblasts, allowing the preservation of their differentiated state and good adhesion properties.
\end{abstract}

Keywords: titanium carbide surface; human primary fibroblasts; human primary chondrocytes; human primary osteoblasts; Atomic Force Microscopy; cell differentiation; cell adhesion

\section{Introduction}

In the last years, the in vitro cell culture fields have undergone significant developments, especially in their application to a wide range of research areas, such as screening of molecules to be used in the treatments of pathologies, toxicology and disease studies [1]. A number of concerns has been raised regarding the quality of cell cultures, with particular focus on the surfaces used to propagate cells. While plastic flasks and dishes have been available since the 1960s, to perform in vitro cell culture, nowadays, most of these vessels are in polystyrene, a long carbon chain polymer with benzene rings attached to carbons. This material can be easily bent to form any kind of container or support, which has excellent optical clarity and simple sterilization processes. The main disadvantage is the 
hydrophobicity of polystyrene, which does not allow cell attaching [2]. For this reason, these vessels are modified to have a more hydrophilic surface by either corona discharge under atmospheric conditions or gas-plasma under vacuum.

Treated-polystyrene still has limitations, especially in serum-free culture conditions and to maintain differentiated cell functions in primary cultures. In order to bypass these problems, different polystyrene coatings have been proposed, involving both synthetic polymers, i.e., poly-D-lysine, which confers a positive charge to surface and biological materials, such as extracellular matrix components (ECM) like collagens, fibronectin, vitronectin or laminin [3-5]. The poly-D-lysine is more suitable for cell culture but also time-consuming and expensive [5]. The biological coating with ECM components from specific tissues could provide a suitable microenvironment to cultivate cells, avoiding their dedifferentiation. Unfortunately, the most common biological coating strategies employ purified matrix proteins, which produce a microenvironment for the cell growth that is different from the in vivo conditions, and this can lead to modifications of the cellular behavior. Other strategies include the use of tissue-derived ECM, but this implies that the cells are grown in 3D in a scaffold and not in monolayer (2D) [6].

Another weakness of cell-culture models is the use of cell lines, which have been in vitro immortalized or obtained by cancers. These cells are only slightly representative of tissue cells, while primary cells allow greater predictability of the in vivo behavior in the presence of putative drugs or in the study of diseases progression. Unfortunately, the primary cells are much more sensitive to their environment and could respond differently if cultured on particular surfaces.

Actin is the most representative protein of the cytoskeleton of eukaryotic cells [7]. The cytoskeleton, by integrating the activity of cytoplasmic proteins and organelles, coordinates the physical and biochemical connection of cells to the external environment [8]. Thus, the study of actin filaments is a good method to analyze the cell behavior and the interaction between the cells and the growth environment.

Moreover, to analyze the phenotype of cells during in vitro culture, several growth factors can be measured. The Osteocalcin (OC) production is typical of osteoblasts (hOBs) [9], Fibroblast Growth Factor-2 (FGF-2) is typical of fibroblasts (FBs) [10] and the Bone Morphogenetic Protein-2 (BMP-2) is involved in chondrocyte (HPCs) metabolic activity [11].

Fibroblasts, chondrocytes and osteoblasts are cells involved in production of extracellular matrix components in their in vivo tissues, skin, cartilage and bone, respectively. Among the ECM components, they produce the collagens, mainly Collagen type I (Coll I) in skin and bone and Collagen type II (Coll II) in cartilage [12-14]. Prolonged 2D cell culture can lead to the downregulation of the production of these ECM components, and the decrease of collagen production indicates that cells are losing their differentiated state; thus, a good practice to verify the suitability of the cell culture conditions is to measure the synthesis of collagens.

Several instruments are available to characterize specific physiologically related properties of biologically related microscopic samples [15]. Among these, Atomic Force Microscopy (AFM) is nowadays a tool commonly employed to characterize at high resolution a wide range of samples at nanometer level, with negligible perturbations, minimal sample preparation and providing a truly three-dimensional quantitative mapping at the nanoscale of the studied material [16,17]. In particular, the use of this quantitative high-resolution technique has demonstrated to be very appropriate to monitor the properties of the cell wall and cytoskeleton in different cell types and various conditions [18-20] and is the ideal label-free tool to monitor the actin cytoskeleton in cells [21,22]. The high resolution of AFM imaging allows highlighting of the fine details, i.e., roughness of the cell membrane [23] or stiffer structures present near the cellular membrane, such as large actin filaments, which are typical of good cellular spreading on the substrate and indicative of a good cell-substrate interaction and of a stronger attachment [18].

Recently, in our laboratory, nanostructured titanium surfaces have been analyzed, with the aim to find a surface with the best osseointegration features [24,25]. Titanium is used for most types of 
implants; moreover, modified titanium surfaces are more suitable for osseointegration, due to the increased wettability or to their microstructural features, such as the surface micro- and nano-roughness, which is very beneficial to cell growth and differentiation [26]. The coating of titanium with hard and highly biocompatible titanium carbide layer (TiC), by ion plating plasma-assisted deposition (IPPA), has been shown with a wide range of characterization techniques, ranging from XPS to AFM and SEM, to be resistant, reliable and with a well-defined chemical structure [27-30]. One more positive aspect of IPPA-deposited $\mathrm{TiC}$ is that it is inexpensive and can easily be introduced in the substrate preparation industrial procedures.

Taking into account these findings, we studied the adhesion, proliferation and morphology of cells on nanostructured $\mathrm{TiC}$ surfaces, comparing them to both cell-culture-treated polystyrene dishes and poly-D-lysinated glass slides (poly-D-Lys). For a more reliable investigation, we chose to use human primary cells, isolated from patients undergoing surgical treatment. Three different types of cells were studied, fibroblasts (FBs), osteoblasts (hOBs) and chondrocytes (HPCs), in order to verify whether nanostructured $\mathrm{TiC}$ could stimulate cells adhesion and thus be considered a good cell culture surface.

\section{Results}

\subsection{Cell Adhesion on Polystyrene, Poly-D-Lys and TiC}

Cells were seeded on the polystyrene, poly-D-Lys and Tic surfaces, incubated for $48 \mathrm{~h}$ and immunostained to evaluate the resulting actin filament organization. The number of FBs seemed higher on TiC compared both to polystyrene and poly-D-Lys. Moreover, FBs formed a three-dimensional structure on $\mathrm{TiC}$, as shown by the actin filaments that were arranged on different planes. Similarly, the number of HPCs present on poly-D-Lys and TiC seemed higher than the number observed on polystyrene. Remarkably, the cells grown on TiC presented a peculiar structure with the nucleus on one side and the cytoplasm on the other. Moreover, hOBs seemed more abundant on TiC in comparison with polystyrene and poly-D-Lys and on TiC the cells formed a more complex network, with a larger number of contact points among cells (Figure 1).
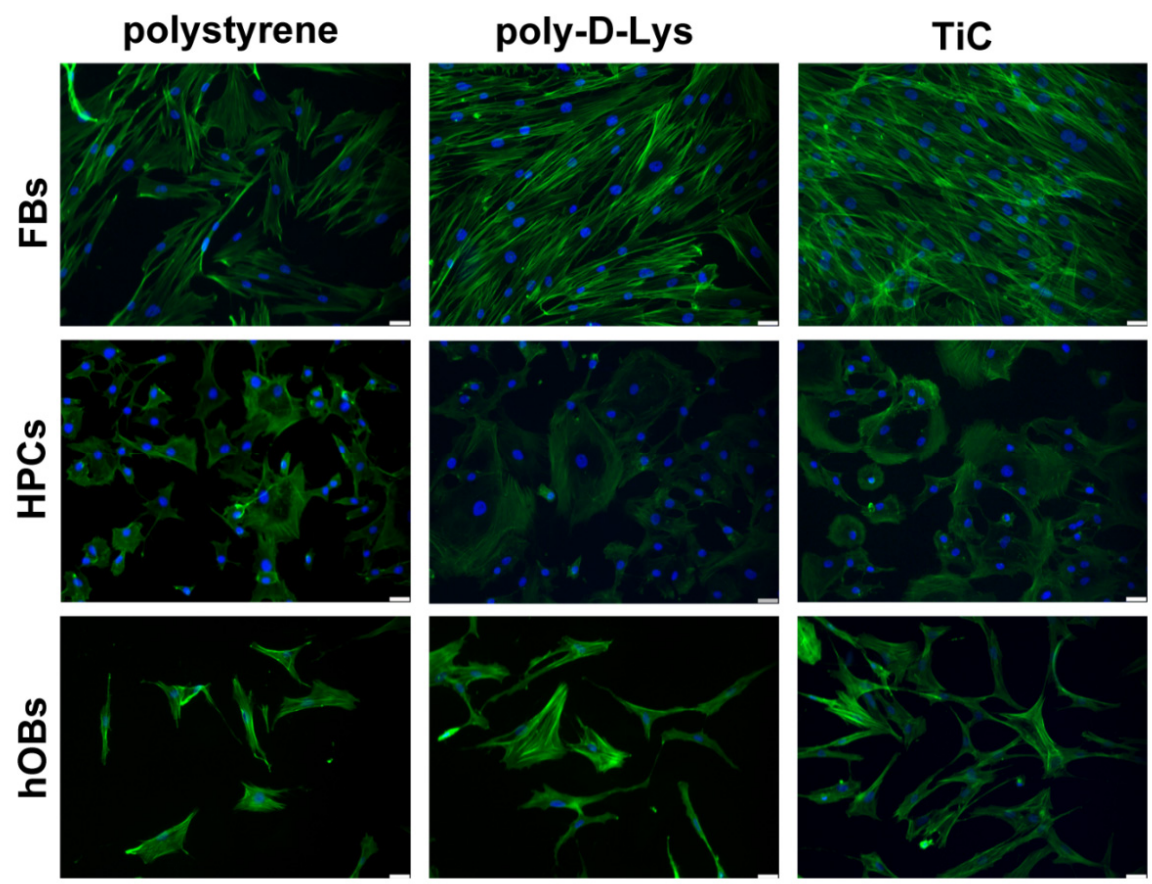

Figure 1. Organization in fibroblasts (FBs), chondrocytes (HPCs) and osteoblasts (hOBs) seeded on polystyrene, poly-D-Lysine-coated glass (poly-D-Lys) and titanium-carbide-coated glass (TiC). Cells were seeded, and after $48 \mathrm{~h}$, they were analyzed by Immunofluorescence by using Phalloidin Alexa Fluor 488. Nuclei were stained with DAPI (original magnification 20x, scale bar $=50 \mu \mathrm{m}$ ). 


\subsection{Production of Osteocalcin, Fibroblast Growth Factor and Bone Morphogenetic Protein 2}

To verify whether the substrate chemistry stimulated the cells to produce factors involved in their metabolism, the amount of FGF-2, BMP-2 and OC was measured in the cell culture medium of FBs, HPCs and hOBs, respectively (Figure 2). FBs cultured on $\mathrm{TiC}$ for $24 \mathrm{~h}$ produced a higher amount of FGF compared to FBs cultured on polystyrene and poly-D-Lys, even if the increase was not statistically significant. After $72 \mathrm{~h}$, the amount of FGF-2 was undetectable in the medium of the cells cultured on polystyrene and TiC, while the cells on poly-D-Lys were still producing FGF-2. Compared to polystyrene, at $24 \mathrm{HPC}$ produced statistically significant $(P \leq 0.05)$ higher amounts of BMP-2, both on poly-D-Lys and on TiC. Finally, hOBs produced a statistically significant larger amount of OC when cultured on TiC compared to polystyrene and poly-D-Lys after $72 \mathrm{~h}$ culture.

FGF-2

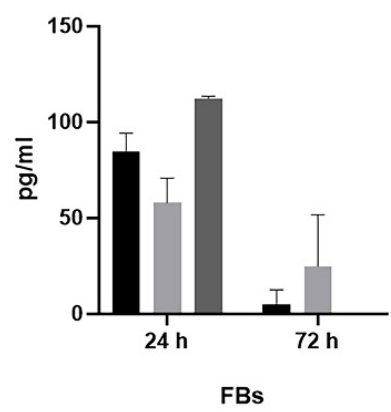

BMP-2

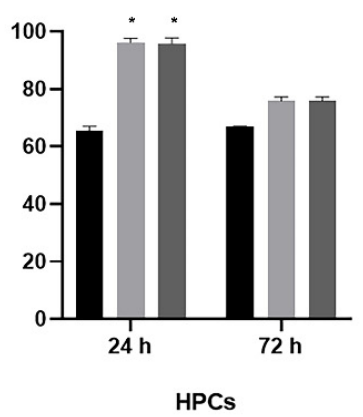

OC

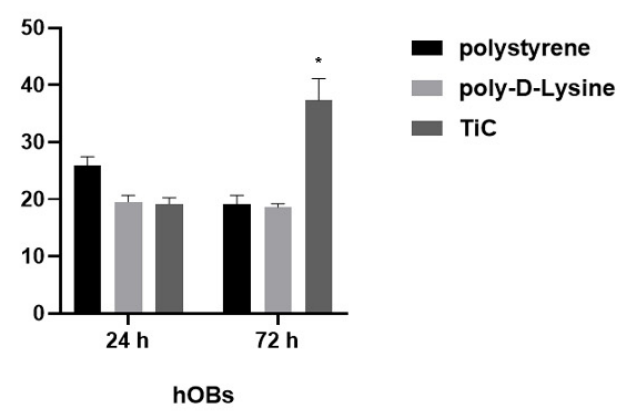

Figure 2. Measureof FGF-2, BMP-2 and OC secretion in cell culture medium. Fibroblasts, chondrocytes and osteoblasts were seeded on polystyrene, poly-D-lysine-coated glass (poly-D-Lys) and titanium carbide-coated glass (TiC), and after 24 or $72 \mathrm{~h}$, the cell culture medium was analyzed for Fibroblast Growth Factor-2 (FGF-2), Bone Morphogenetic Protein-2 (BMP-2) and Osteocalcin (OC) by ELISA method, in fibroblasts, chondrocytes and osteoblasts, respectively. Results (in pg/mL) are expressed as mean \pm standard error, obtained in three different experiments. ${ }^{*} P \leq 0.05$.

\subsection{Collagens Production}

The production of Coll I in FBs and hOBs and Coll II in HPCs was analyzed by immunofluorescence after seven days' culture, to allow cells to produce the collagens. The FBs layered on TiC showed a larger accumulation of Coll I compared to the cells plated on polystyrene and poly-D-Lys. Moreover, the chondrocytes appeared to deposit Coll II, which caused the cells to acquire a less elongated shape. Once again, the nucleus was on one side and the collagen deposit was on the other side of the cells. Finally, the hOBs deposited large amount of Coll I on poly-D-Lys and mainly on TiC (Table 1 and Figure 3).

Table 1. Densitometric analysis of Collagen type I on fibroblasts (FBs) and osteoblasts (hOBs) and Collagen type II on chondrocytes (HPCs,) seeded on polystyrene, poly-D-Lysine-coated glass (poly-D-Lys) and titanium carbide-coated glass (TiC). Integrated density values of fluorescence were obtained by using ImageJ software. The numbers reported in table represent the sum of all pixel intensities in the region of interest, in this case the whole picture.

\begin{tabular}{cccc}
\hline & Polystyrene & Poly-D-Lys & TiC \\
\hline Coll I in FBs & 1549 & 1653 & 2465 \\
Coll II in HPCs & 2236 & 2673 & 3641 \\
Coll I in hOBs & 949 & 2933 & 4381 \\
\hline
\end{tabular}




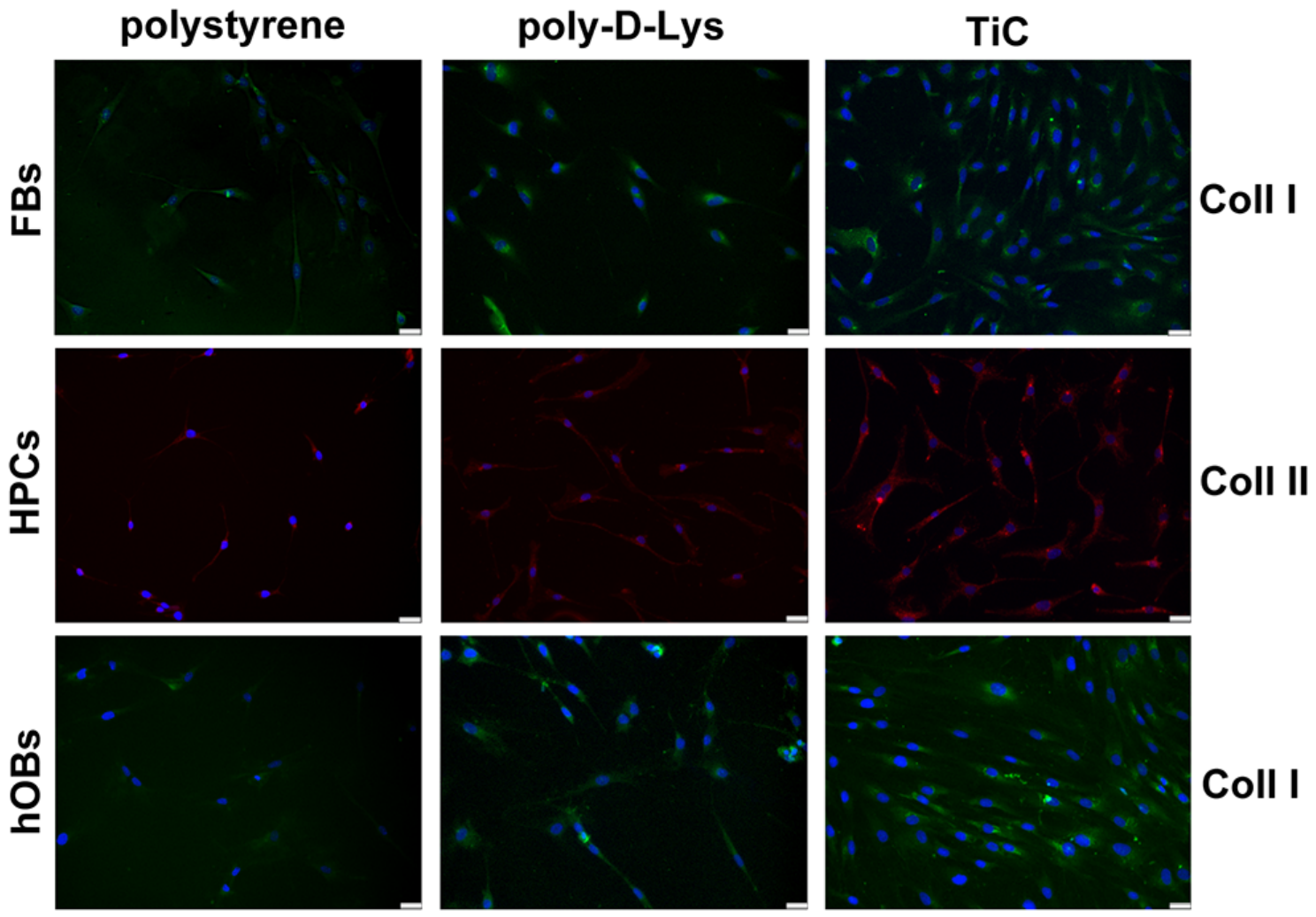

Figure 3. Imagesof collagens in fibroblasts (FBs), chondrocytes (HPCs) and osteoblasts (hOBs) seeded on polystyrene, poly-D-Lysine-coated glass (poly-D-Lys) and titanium-carbide-coated glass (TiC). Cells were seeded, and after seven days, they were analyzed by immunofluorescence, using anti-collagen type I (Coll I) or anti-collagen type II (Coll II) and Alexa Fluor 488 (green) or 576 (red) secondary antibodies. Nuclei were stained with DAPI (original magnification 20×, scale bar $=50 \mu \mathrm{m}$ ).

\subsection{AFM Analysis}

We performed a series of AFM images on cells grown for $48 \mathrm{~h}$ on the different substrates. All the images were performed on entire cells, to determine their overall form and height of the cells, and focusing on the extremities, where the substrate-cell interaction is usually focused. As shown in Figure 4, the cells evidenced different morphological properties, depending on the substrate. The form of the cell extremities is much different in the three cases, with the cells growing on TiC evidencing flatter and more spread extremities. The most evident difference between cells grown on polystyrene and poly-D-Lys compared to those grown on $\mathrm{TiC}$ is in the presence, only in this latter case, of long actin filaments. In addition, we performed the averaging of the height of the entire cells in the different conditions. The results are summarized in Table 1 and evidence how the cells grown on $\mathrm{TiC}$ have a lower average height compared to those grown on poly-D-Lys and polystyrene. 


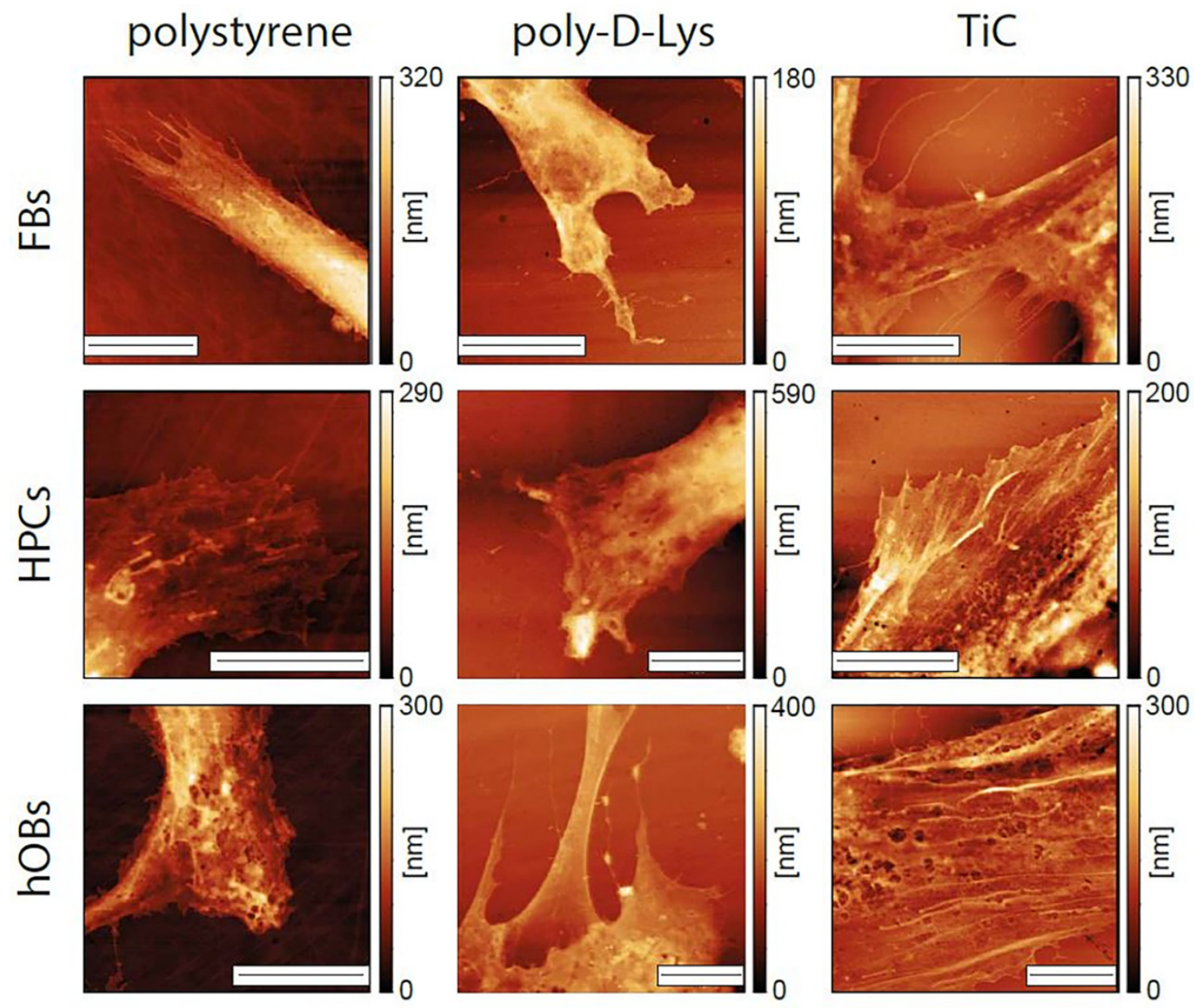

Figure 4. Images of the extremities of fibroblasts (FBs), chondrocytes (HPCs) and osteoblasts (hOBs) seeded on polystyrene, poly-D-Lysine-coated glass (poly-D-Lys) and titanium carbide-coated glass (TiC). Cells were seeded, and after $48 \mathrm{~h}$ were immobilized and analyzed by contact-mode AFM. The scale bar represents $10 \mu \mathrm{m}$.

\section{Discussion}

In the last decades, the in vitro cell culture methods have undergone a strong development, due to their employment in many research areas, such as drug development, toxicology and disease studies [31]. However, several concerns have been raised, regarding in particular the environment in which cells are cultivated [1]. Usually, in the field of drug discovery, two-dimensional (2D) monolayer cell culture conditions are used and they have proven to be an effective and convenient method to perform analyses. Nevertheless, 2D cell cultures show disadvantages regarding the loss of tissue-specific architecture, particularly in those tissues where the interactions between cells and matrix is very desirable, such as skin [32], cartilage [33] and bone [34]. Nowadays, 2D cell cultures are performed by using treated-polystyrene or coated-glass, but a certain number of limitations remain. Cell cultures on a treated-polystyrene surface can lead to loss of differentiated status and/or cell functions, those on coated surfaces, as with poly-D-lysine, are time-consuming and expensive, and the biological coating with ECM components could provide a microenvironment for the cell growth that is different from the in vivo conditions, leading to modifications of the cellular behavior; [3-5]. In the last years, we studied nanostructured TiC material, and considering all its features [24,25], we decided to evaluate the 2D cell culture on this surface in comparison with cell cultures on treated-polystyrene and poly-D-Lysine-coated glass. The titanium carbide layer was produced by IPPA deposition [27-30] directly on glass slides, obtaining surfaces with $25 \%$ light transmittance ability. This feature allows to perform several kinds of experiments on cells, as immunofluorescence, while retaining the good 
characteristics of nanostructured titanium. Moreover, the IPPA deposition method is not expensive and can be easily introduced in the industrial procedures for glass or plastic cell substrates.

Actin is the most representative protein of the cytoskeleton of eukaryotic cells [7] and it is crucial for the maintenance of cell structure, polarity and mobility [35]. Most mammalian cells grow in adhesion and need, for their survival, to be attached to a surface. To analyze the effects of the supports on cell growth, we used human primary cells, which are much more sensitive to the underlying environment compared to immortalized cells.

The analysis of the actin organization is a method to evaluate the adhesion of cells to a substrate. Very interestingly, the cells cultivated on TiC showed an actin structure more similar to the organization they have in the tissues, with widespread cells bearing abundance of stress fibers (Figures 1 and 4 ). The FBs were arranged in 3D structure, showing filaments disposed on different planes (Figure 1). HPCs formed a particular structure with the nucleus on one side and the cytoplasm on the other side (Figures 1 and 3), resembling the same structure previously observed in chondrocytes cultured in 3D systems [36]. Finally, the hOBs showed on TiC an arrangement which is much more resembling to that commonly found in bone: an increased production of collagens and other ECM components and subsequently an improved differentiation in osteocytes, that have several filaments used to stay in contact with other cells and with the bone microenvironment. Both of these features were more present in the hOBs grown on $\mathrm{TiC}$, compared to the cells cultivated on poly-D-Lysine and polystyrene (Figures 2 and 4). This is confirmed by the AFM images, where the cells grown on TiC substrates show well-defined actin filaments which are not evident on the membrane of cells grown on polystyrene and poly-D-Lys. Indeed, the presence of these stress fibers and the overall height of the cells over the substrate indicate that the cells have a better attachment and suggest a higher affinity with TiC (Figure 4). This is also suggested by the cell form and spreading over the substrates and by the average height of the cells, which is much smaller on TiC compared to the other substrates (Table 2). This confirms the results obtained on hOBs grown on the very same substrate $[24,25,28]$ and substantiates that are found with the FBs and HPCs cells.

Table 2. Average height of the cells on the different substratesof fibroblasts (FBs), chondrocytes (HPCs) and osteoblasts (hOBs) seeded on polystyrene, poly-D-Lysine-coated glass (poly-D-Lys) and titanium carbide-coated glass (TiC). The values were obtained by averaging a minimum of eight cells per sample and are presented \pm the standard deviation.

\begin{tabular}{cccc}
\hline & Polystyrene & Poly-D-Lys & TiC \\
\hline FBs & $1.60 \pm 0.14 \mu \mathrm{m}$ & $1.15 \pm 0.21 \mu \mathrm{m}$ & $0.78 \pm 0.16 \mu \mathrm{m}$ \\
\hline HPCs & $1.21 \pm 0.42 \mu \mathrm{m}$ & $1.50 \pm 0.48 \mu \mathrm{m}$ & $0.69 \pm 0.06 \mu \mathrm{m}$ \\
\hline hOBs & $1.1 \pm 0.27 \mu \mathrm{m}$ & $1.18 \pm 0.30 \mu \mathrm{m}$ & $0.79 \pm 0.23 \mu \mathrm{m}$ \\
\hline
\end{tabular}

FBs, belonging to a dermis cell type with mesenchymal origin, play a critical role in epithelial-mesenchymal interactions, wound healing and synthesis and secretion of extracellular matrix components, including collagens [37]. In culture medium, FBs secrete several factors, such as basic fibroblast growth factor (FGF-2). This factor is a heparin-binding protein, which interacts with cell-surface-associated heparan sulfate proteoglycans, and it is involved in many biological processes, such as cell growth and wound healing [38]. Its production is indicative of the ability of cells to adhere to surface and to proliferate; nevertheless, FGFs are secreted in a very low amount from cell cultures [39]. We found that FBs cultivated on TiC produced a higher amount of FGF-2 compared to polystyrene and poly-D-Lys at $24 \mathrm{~h}$, whereas after $72 \mathrm{~h}$, only on poly-D-Lys, a residual production was observed (Figure 2). It is probable that the cells on $\mathrm{TiC}$ had reached, after $72 \mathrm{~h}$, a good level of maturation and adhesion to the growth surface; thus, they did not need to further secrete FGF-2. Moreover, cells on $\mathrm{TiC}$ reached confluence, as shown in Figure 3. In order to allow cells to produce a detectable number of collagens, cells were cultivated for seven days before analysis, and, at this time point, the different confluence of cells on TiC compared to those on polystyrene and poly-D-lys was 
much more evident. Finally, considering that cells were producing more collagen type I compared to the other two substrates (Table 1), we can conclude that they preserved the differentiated status.

HPCs are the only cell type present in cartilage, and their role is to produce and renew the extracellular matrix. BMP-2 is a growth factor used in cell culture, to stimulate mesenchymal cells to differentiate in chondrocytes [35]. HPCs cultured on poly-D-Lys and TiC produced a higher amount of BMP-2 compared to polystyrene; considering that the chondrocytes we used are from adult tissue, the production of BMP-2 by these cells is very promising. Very interesting is also the ability of HPCs cultured on TiC to produce collagen type II (Figure 3), which is almost undetectable on the other two surfaces. Usually, these cells when cultured in 2D dedifferentiate and lose their ability to produce Coll II. TiC, on the other hand, appears to allow the chondrocytes to be maintained in a differentiated state.

Osteoblasts originate by mesenchymal cells and are primarily responsible for the synthesis and deposition of the mineralized, collagen-rich matrix present in the bone tissue [40]. Another very abundant factor present in the bone is osteocalcin, which is produced exclusively by osteoblasts. Osteocalcin is used as a serum marker of bone formation, and is also an indicator of the proliferative and differentiated state of osteoblasts in cell culture. So far, it has been believed to act on bone to regulate the mineralization, but recent studies suggested a broader role for osteocalcin, extending its role to the regulation of the whole body metabolism [41]. Osteoblasts cultivated on TiC produced a statistically significant higher amount of OC compared to polystyrene and poly-D-Lys, and moreover, a higher amount of Coll I, a collagen very abundant in bone matrix (Figures 2 and 3).

\section{Materials and Methods}

Human primary cell isolation. Human primary cells were isolated from patients that underwent surgical treatment, and full ethical consent was obtained from all donors and the Research Ethics Committee, Sapienza University of Roma, approved the study.

Human primary diploid dermal fibroblasts (FBs) were obtained from young adult male patients who underwent circumcision surgery for phimosis. FBs were isolated as previously described [37]; briefly, after scraping away excess fat and subcutaneous tissue, the foreskins were floated in $0.25 \%$ trypsin solution (Sigma Aldrich, Co. Saint Louis, MO, USA), at room temperature, for $1 \mathrm{~h}$, under gentle agitation. Trypsin was neutralized by soybean trypsin inhibitor, and the cells were cultivated in High Glucose Dulbecco's modified Eagle's medium (DMEM) (Sigma Aldrich), supplemented with penicillin/streptomycin, L-glutamine, Na-pyruvate, non-essential amino acids (Sigma Aldrich) and 10\% Fetal Bovine Serum (FBS) (Sigma Aldrich).

Human Primary Chondrocytes (HPCs) were isolated from femoral and tibial condyles and from femoral heads, obtained from patients who underwent a total knee and hip arthroplasty. HPCs were isolated, as previously described, from articular cartilages aseptically dissected from patients, selecting areas of macroscopically normal cartilage [36]. The isolated chondrocytes were grown to $80 \%$ confluence in DMEM (HyClone, Logan, UT, USA) supplemented with L-glutamine, penicillin/streptomycin (Sigma Aldrich) and 10\% Fetal Bovine Serum (FBS).

Human primary osteoblasts (hOBs) were isolated from bone fragments, as previously described [29]. In brief, the bone fragments were washed in sterile phosphate-buffer saline (PBS), minced and treated with $1 \mathrm{mg} / \mathrm{mL}$ collagenase type IV and $0.25 \%$ trypsin for $1 \mathrm{~h}$, at $37^{\circ} \mathrm{C}$, with gentle agitation. Then, hOBs were grown to $80 \%$ confluence in McCoy's medium (Sigma Aldrich) supplemented with L-glutamine, penicillin/streptomycin and 15\% FBS.

To avoid the bias of senescence modification in cell metabolism, mycoplasma-free FB clones between the 5th and 20th in vitro passage were used, whereas HPCs and hOBs were used at first passage (p1).

All types of cells were seeded on test substrates, polystyrene, poly-D-Lys and TiC, at a density of $8 \times 10^{3} / \mathrm{cm}^{2}$, and cultured for the requested times, at $37^{\circ} \mathrm{C}$, in $5 \% \mathrm{CO}_{2}$.

Substrate preparation. Cells were cultured on commercially available cell-culture-treated polystyrene dishes, on home-prepared poly-D-lysinated glass and on nanostructured TiC. 
Glass slides were poly-D-lysinated by adding $50 \mu \mathrm{g} / \mathrm{mL}$ of poly-D-lysine in sterile water, left 10 $\mathrm{min}$ at room temperature and then rinsed with PBS.

Nanostructured TiC film was prepared as previously described [24]; in brief, glass slides were coated with thin film of TiC (10.5 nm) by Ion Plating Plasma Assisted deposition method. The layers allowed the transmission of $25 \%$ of the light, which was enough to perform fluorescence microscope analyses. The TiC slides were previously characterized by XPS, to determine the composition [30].

Immunofluorescence. Cells plated at a density of $8 \times 10^{3} / \mathrm{cm}^{2}$ were analyzed by immunofluorescence, to visualize the actin filaments. Cells were cultured for $48 \mathrm{~h}$ and then washed in PBS, fixed in $4 \%$ paraformaldehyde in PBS for $15 \mathrm{~min}$, at $4{ }^{\circ} \mathrm{C}$, and permeabilized with $0.5 \%$ Triton-X 100 in PBS, for $10 \mathrm{~min}$, at room temperature. After blocking with $3 \%$ bovine serum albumin (BSA) in PBS for $30 \mathrm{~min}$, at room temperature, cells were incubated with Phalloidin Alexa Fluor 488 (Immunological Sciences, Rome, Italy) 1:40, for $20 \mathrm{~min}$, at room temperature. Cells were ultimately washed in PBS and incubated with DAPI (Invitrogen, ThermoFisher Scientific, Waltham, MA, USA), to visualize the nuclei. To analyze the collagens, cells, after blocking, were incubated at $1 \mathrm{~h}$, at room temperature, with mouse monoclonal anti-Collagen I antibody (Santa Cruz Biotechnology, Inc, Dallas, TE, USA) or with mouse monoclonal anti-Collagen II antibody (Abcam, Cambridge, UK), washed with PBS and then incubated for $1 \mathrm{~h}$, at room temperature, with Alexa Fluor 488 or Alexa Fluor 568 goat anti-mouse (Immunological Sciences), respectively. Slides were washed and then incubated with DAPI (Invitrogen, ThermoFisher Scientific), to visualize the nuclei. The images were captured by optical microscope Leica DM IL LED, using AF6000 modular Microscope, and analyzed with Leica DM microscope (Leica Microsystem, Milan, Italy).

Densitometric analysis. The free software ImageJ (https:/imagej.nih.gov/ij/) was used to perform the densitometric analysis of collagen production. For each cell culture condition, the integrated density values of fluorescence were considered. The sum of all pixel intensities in the region of interest is listed in Table 1.

ELISA. Concentration of Bone Morphogenetic Protein (BMP-2), Osteocalcin (OC) and Fibroblast Growth Factor (FGF-2) in culture medium was measured by BMP-2, OC and FGF-2 ELISA kit Fine Test (Fine Biotech Co., Ltd., Wuhan, China), respectively, according to the manufacturers' instructions.

Atomic Force Microscope. The experiments were conducted, using a commercial FlexAFM (Nanosurf, Liestal, Switzerland) installed over an inverted optical microscope Olympus IX 70 (Olympus, Rungis, France) equipped with a high-resolution camera (F-View-II-Soft Imaging System GmbH, Münster, Germany). We used silicon nitride BrukerDNP-10 probes (Bruker probes, Manning Park Billerica, MA, USA), choosing the cantilever with nominal elastic constant of $0.06 \mathrm{~N} / \mathrm{m}$ and a 4 -sided pyramidal tip shape with apical radius of $10 \mathrm{~nm}$. Prior to each day of measurements, the cantilevers were calibrated, using a built-in thermal calibration protocol [41].

The cells on the different substrates were fixed, using $0.5 \%$ glutaraldehyde in PBS, for $3 \mathrm{~h}$, at $4{ }^{\circ} \mathrm{C}$, and then washed in PBS, kept in ultra-pure water, and finally air-dried prior to imaging. The AFM images were collected in contact mode, with an applied force of $10 \mathrm{nN}$. All images were acquired with a minimum of 512 points per line and with an acquisition speed of 2 lines per second for all the presented $30 \times 30 \mu \mathrm{m}$ images. The images are presented without any filter; only a background subtraction and plane alignment were performed. A minimum of 10 cells per sample were analyzed.

\section{Conclusions}

In this manuscript, we compared the proliferation and adhesion of three cell types, FBs, HPCs and hOBs, on three different substrates: polystyrene, poly-D-Lysine and glass coated with titanium carbide. $\mathrm{TiC}$ appeared as an excellent choice for cell cultivation substrate. Indeed, we showed how this surface allows maintaining the cells in their differentiated status when cultured in 2D conditions, as shown by the production of collagens, which resulted in being almost undetectable in cells cultivated both on polystyrene and on poly-D-Lys. The AFM images confirmed these results, highlighting how the three different cell lines grown on $\mathrm{TiC}$ produced a more complete adhesion in comparison to the other 
commonly employed substrates. Overall, this underscores how $\mathrm{TiC}$ is an excellent additional layer to produce a cell-growth environment. Furthermore, since the deposition of hard layer of titanium carbide on glass using ion plating plasma-assisted deposition is an inexpensive method which is very easily implemented in an industrial platform, we can propose this as an easy and straightforward addition to the substrate preparation protocols, to improve their biocompatibility.

Author Contributions: Conceptualization, A.S.d. and R.S.; methodology and investigation, M.L., A.M., R.C., G.L. and P.D.V.; data curation, A.S.d., M.L., A.M. and G.L.; writing-original draft preparation, A.S.d., M.L. and G.L. All authors have read and agreed to the published version of the manuscript.

Funding: Giovanni Longo, Anna Scotto d'Abusco and Roberto Scandurra were partially supported by the Italian Health Ministry Grant GR-2009-1605007.

Acknowledgments: The authors would like to thank Misiano for titanium carbide deposition by IPPA method.

Conflicts of Interest: The authors declare no conflict of interest.

\section{References}

1. Pamies, D.; Bal-Price, A.; Simeonov, A.; Tagle, D.; Allen, D.; Gerhold, D.; Yin, D.; Pistollato, F.; Inutsuka, T.; Sullivan, K.; et al. Good cell culture practice for stem cells \& stem-cell-derived models. ALTEX 2017, 34, 95-132.

2. Lerman, M.J.; Lembong, J.; Muramoto, S.; Gillen, G.; Fisher, J.P. The Evolution of Polystyrene as a Cell Culture Material. Tissue Eng. Part B Rev. 2018, 24, 359-372. [CrossRef] [PubMed]

3. Williams, C.M.; Engler, A.J.; Slone, R.D.; Galante, L.L.; Schwarzbauer, J.E. Fibronectin expression modulates mammary epithelial cell proliferation during acinar differentiation. Cancer Res. 2008, 69, 3185-3192. [CrossRef] [PubMed]

4. Brafman, D.A.; Shah, K.D.; Fellner, T.; Chien, S.; Willert, K. Defining long-term maintenance conditions of human embryonic stem cells with arrayed cellular microenvironment technology. Stem Cells Dev. 2009, 18, 1141-1154. [CrossRef] [PubMed]

5. Ho, M.; Yu, D.; Davidsion, M.C.; Silva, G.A. Comparison of standard surface chemistries for culturing mesenchymal stem cells prior to neural differentiation. Biomaterials 2006, 27, 4333-4339. [CrossRef] [PubMed]

6. DeQuach, J.A.; Mezzano, V.; Miglani, A.; Lange, S.; Keller, G.M.; Sheikh, F.; Christman, K.L. Simple and high yielding method for preparing tissue specific extracellular matrix coatings for cell culture. PLoS ONE 2010,5, e13039. [CrossRef] [PubMed]

7. Pollard, T.D. Actin and actin-binding proteins. Cold Spring Harb. Perspect. Biol. 2016, 8, a018226. [CrossRef]

8. Fletcher, D.A.; Mullins, R.D. Cell mechanics and the cytoskeleton. Nature 2010, 463, 485-492. [CrossRef]

9. Lotz, E.M.; Cohen, D.J.; Schwartz, Z.; Boyan, B.D. Titanium implant surface properties enhance osseointegration in ovariectomy induced osteoporotic rats without pharmacologic intervention. Clin. Oral Implant Res. 2020, in press. [CrossRef]

10. Sumbal, J.; Koledova, Z. FGF signaling in mammary gland fibroblasts regulates multiple fibroblast functions and mammary epithelial morphogenesis. Development 2019, 146, 185306. [CrossRef]

11. Wang, Z.; Hutton, W.C.; Tim Yoon, S. ISSLS prize winner: Effect of link protein peptide on human intervertebral disc cells. Spine 2013, 38, 1501-1507. [CrossRef] [PubMed]

12. Florencio-Silva, R.; Sasso, G.R.D.S.; Sasso-Cerri, E.; Simões, M.J.; Cerri, P.S. Biology of Bone Tissue: Structure, Function, and Factors That Influence Bone Cells. Biomed Res. Int. 2015, 2015, 421746. [CrossRef] [PubMed]

13. Goldring, M.B. Update on the biology of the chondrocyte and new approaches to treating cartilage diseases. Best Pract. Res. Clin. Rheumatol. 2006, 20, 1003-1025. [CrossRef] [PubMed]

14. Thulabandu, V.; Chen, D.; Atit, R.P. Dermal fibroblast in cutaneous development and healing. Wiley Interdiscip. Rev. Dev. Biol. 2018, 7, e307. [CrossRef]

15. Dinarelli, S.; Girasole, M.; Longo, G. Methods for atomic force microscopy of biological and living specimens. Methods Mol. Biol. 2018, 1814, 529-539.

16. Kasas, S.; Longo, G.; Dietler, G. Mechanical properties of biological specimens explored by atomic force microscopy. J. Phys. D Appl. Phys. 2013, 46, 133001. [CrossRef]

17. Longo, G.; Kasas, S. Effects of antibacterial agents and drugs monitored by atomic force microscopy. Wiley Interdiscip. Rev. Nanomed. Nanobiotechnol. 2014, 6, 230-244. [CrossRef] 
18. Japaridze, A.; Muskhelishvili, G.; Benedetti, F.; Gavriilidou, A.F.M.; Zenobi, R.; De Los Rios, P.; Longo, G.; Dietler, G. Hyperplectonemes: A Higher Order Compact and Dynamic DNA Self-Organization. Nano Lett. 2017, 17, 1938-1948. [CrossRef]

19. Jiangtao, Z.; Francesco, S.R.; Manuela, R.Z.; Georg, M.; Giovanni, L.; Sergey, K.S. Effects of sedimentation, microgravity hydrodynamic mixing and air-water interface on $\alpha$-synuclein amyloid formation. Chem. Sci. 2020, 11, 3687-3693.

20. Ruggeri, F.S.; Longo, G.; Faggiano, S.; Lipiec, E.; Pastore, A.; Dietler, G. Infrared nanospectroscopy characterization of oligomeric and fibrillar aggregates during amyloid formation. Nat. Commun. 2015, 6, 1-9. [CrossRef]

21. Longo, G.; Rio, L.M.; Roduit, C.; Trampuz, A.; Bizzini, A.; Dietler, G.; Kasas, S. Force volume and stiffness tomography investigation on the dynamics of stiff material under bacterial membranes. J. Mol. Recognit. 2012, 25, 278-284. [CrossRef]

22. Longo, G.; Rio, L.M.; Trampuz, A.; Dietler, G.; Bizzini, A.; Kasas, S. Antibiotic-induced modifications of the stiffness of bacterial membranes. J. Microbiol. Methods 2013, 93, 80-84. [CrossRef] [PubMed]

23. Girasole, M.; Pompeo, G.; Cricenti, A.; Longo, G.; Boumis, G.; Bellelli, A.; Amiconi, S. The how, when, and why of the aging signals appearing on the human erythrocyte membrane: An atomic force microscopy study of surface roughness. Nanomed. Nanotechnol. Biol. Med. 2010, 6, 760-768. [CrossRef] [PubMed]

24. Longo, G.; Ioannidu, C.A.; Scotto d'Abusco, A.; Superti, F.; Misiano, C.; Zanoni, R.; Politi, L.; Mazzola, L.; Iosi, F.; Mura, F.; et al. Improving osteoblast response in vitro by a nanostructured thin film with titanium carbide and titanium oxides clustered around graphitic carbon. PLoS ONE 2016, 11, e0152566. [CrossRef]

25. Veronesi, F.; Giavaresi, G.; Fini, M.; Longo, G.; Ioannidu, C.A.; Scotto d'Abusco, A.; Superti, F.; Panzini, G.; Misiano, C.; Palattella, A.; et al. Osseointegration is improved by coating titanium implants with a nanostructured thin film with titanium carbide and titanium oxides clustered around graphitic carbon. Mater. Sci. Eng. C 2017, 70, 264-271. [CrossRef]

26. Anselme, K. Biomaterials and interface with bone. Osteoporos. Int. 2011, 22, 2037-2042. [CrossRef]

27. Brama, M.; Rhodes, N.; Hunt, J.; Ricci, A.; Teghil, R.; Migliaccio, S.; Rocca, C.D.; Leccisotti, S.; Lioi, A.; Scandurra, M.; et al. Effect of titanium carbide coating on the osseointegration response in vitro and in vivo. Biomaterials 2007, 28, 595-608. [CrossRef]

28. Longo, G.; Girasole, M.; Pompeo, G.; Cricenti, A.; Misiano, C.; Acclavio, A.; Tizzoni, A.C.; Mazzola, L.; Santini, P.; Politi, L.; et al. Effect of titanium carbide coating by ion plating plasma-assisted deposition on osteoblast response: A chemical, morphological and gene expression investigation. Surf. Coat. Technol. 2010, 204, 2605-2612. [CrossRef]

29. Mazzola, L.; Bemporad, E.; Misiano, C.; Pepe, F.; Santini, P.; Scandurra, R. Surface analysis and osteoblasts response of a titanium oxi-carbide film deposited on titanium by Ion Plating Plasma Assisted (IPPA). J. Nanosci. Nanotechnol. 2011, 11, 8754-8762. [CrossRef]

30. Zanoni, R.; Ioannidu, C.A.; Mazzola, L.; Politi, L.; Misiano, C.; Longo, G.; Falconieri, M.; Scandurra, R. Graphitic carbon in a nanostructured titanium oxycarbide thin film to improve implant osseointegration. Mater. Sci. Eng. C 2015, 46, 409-416. [CrossRef]

31. Jaroch, K.; Jaroch, A.; Bojko, B. Cell cultures in drug discovery and development: The need of reliable in vitro-in vivo extrapolation for pharmacodynamics and pharmacokinetics assessment. J. Pharm. Biomed. Anal. 2018, 147, 297-312. [CrossRef] [PubMed]

32. Lopreiato, M.; Cocchiola, R.; Falcucci, S.; Leopizzi, M.; Cardone, M.; Di Maio, V.; Brocco, U.; D’Orazi, V.; Calvieri, S.; Scandurra, R.; et al. The Glucosamine-derivative NAPA Suppresses MAPK Activation and Restores Collagen Deposition in Human Diploid Fibroblasts Challenged with Environmental Levels of UVB. Photochem. Photobiol. 2020, 96, 74-82. [CrossRef] [PubMed]

33. Stoppoloni, D.; Politi, L.; Leopizzi, M.; Gaetani, S.; Guazzo, R.; Basciani, S.; Moreschini, O.; De Santi, M.; Scandurra, R.; Scotto d'Abusco, A. Effect of glucosamine and its peptidyl-derivative on the production of extracellular matrix components by human primary chondrocytes. Osteoarthr. Cartil. 2015, 23, 103-113. [CrossRef] [PubMed]

34. Blair, H.C.; Larrouture, Q.C.; Li, Y.; Lin, H.; Beer-Stoltz, D.; Liu, L.; Tuan, R.S.; Robinson, L.J.; Schlesinger, P.H.; Nelson, D.J. Osteoblast differentiation and bone matrix formation in vivo and in vitro. Tissue Eng. Part B Rev. 2017, 23, 268-280. [CrossRef] [PubMed] 
35. Contentin, R.; Demoor, M.; Concari, M.; Desancé, M.; Audigié, F.; Branly, T.; Galéra, P. Comparison of the Chondrogenic Potential of Mesenchymal Stem Cells Derived from Bone Marrow and Umbilical Cord Blood Intended for Cartilage Tissue Engineering. Stem Cell Rev. Rep. 2020, 16, 126-143. [CrossRef] [PubMed]

36. Coumoul, X.; Deng, C.X. Roles of FGF Receptors in Mammalian Development and Congenital Diseases. Birth Defects Res. Part CEmbryo Today Rev. 2003, 69, 286-304. [CrossRef] [PubMed]

37. Wong, T.; McGrath, J.A.; Navsaria, H. The role of fibroblasts in tissue engineering and regeneration. $\mathrm{Br}$. J. Dermatol. 2007, 156, 1149-1155. [CrossRef]

38. Karsenty, G.; Ferron, M. The contribution of bone to whole-organism physiology. Nature 2012, 481, 314-320. [CrossRef]

39. Abdian, N.; Ghasemi-Dehkordi, P.; Hashemzadeh-Chaleshtori, M.; Ganji-Arjenaki, M.; Doosti, A.; Amiri, B. Comparison of human dermal fibroblasts (HDFs) growth rate in culture media supplemented with or without basic fibroblast growth factor (bFGF). Cell Tissue Bank. 2015, 16, 487-495. [CrossRef]

40. Zoch, M.L.; Clemens, T.L.; Riddle, R.C. New insights into the biology of osteocalcin. Bone 2016, 82, 42-49. [CrossRef]

41. Hutter, J.L.; Bechhoefer, J. Calibration of atomic-force microscope tips. Rev. Sci. Instrum. 1993, 64, 1868-1873. [CrossRef]

(C) 2020 by the authors. Licensee MDPI, Basel, Switzerland. This article is an open access article distributed under the terms and conditions of the Creative Commons Attribution (CC BY) license (http://creativecommons.org/licenses/by/4.0/). 